\title{
Limbic System Structures Differentially Contribute to Exploratory Trip Organization of the Rat
}

\author{
Shawn S. Winter, ${ }^{1,2 *}$ Jenny R. Köppen, ${ }^{1}$ Tialia B.N. Ebert, ${ }^{1}$ and Douglas G. Wallace ${ }^{1 *}$
}

\begin{abstract}
The role of limbic system structures in spatial orientation continues to be debated. The hippocampus (HPC) has been implicated in encoding symbolic representations of environments (i.e., cognitive map), whereas entorhinal cortex (EC) function has been implicated in self-movement cue processing (i.e., dead reckoning). These distinctions largely depend on the electrophysiological characteristics of cells within these regions and behavioral tasks that typically fail to dissociate environmental and self-movement cue processing. Topographic and kinematic characteristics of exploratory trip organization have been shown to differentially depend on environmental and self-movement cue processing. The present study examines the effects of either HPC or EC lesions on exploratory trip organization under varying lighting conditions. HPC lesions selectively impaired all measures of performance under dark conditions, but spared all measures of performance under light conditions. EC lesions impaired kinematic measures related to distance estimation under all conditions and impaired all measures of performance under light conditions. These results provide evidence that the HPC is involved in processing self-movement cues but not environmental cues, and EC is involved in processing distance estimates generated from either self-movement or environmental cues. These observations provide further support for serial processing of self-movement cues through limbic system structures that converge on the HPC. $\odot 2012$ Wiley Periodicals, Inc.
\end{abstract}

KEY WORDS: entorhinal cortex; hippocampus; dead reckoning; spontaneous exploration

\section{INTRODUCTION}

Spatial orientation is essential for locating resources and avoiding predation. Considering these survival pressures and a changing environment, it is not surprising that natural selection may favor animals that can use environmental (i.e., visual, olfactory, and auditory) and self-movement

\footnotetext{
${ }^{1}$ Psychology Department, Northern Illinois University, DeKalb, Illinois; ${ }^{2}$ Psychology and Brain Science Department, Dartmouth College, Hanover, New Hampshire

Abbreviations used: EC, entorhinal cortex; HD, head direction; HPC, hippocampus.

This project was work conducted as partial fulfillment for the degree Doctor of Philosophy.

Grant sponsor: Wellcome Trust Senior Research Fellowship in Basic Biomedical Science

*Correspondence to: Shawn S. Winter, Psychology and Brain Science Department, Dartmouth College, Hanover, NH 03755, USA. E-mail: Shawn.S.Winter@Dartmouth.edu or Douglas G. Wallace, Psychology Department, Northern Illinois University, DeKalb, IL 60115, USA. E-mail: dwallace@niu.edu

Accepted for publication 9 September 2012

DOI 10.1002/hipo.22075

Published online 4 October 2012 in Wiley Online Library (wileyonlinelibrary.com).
}

(i.e., vestibular, proprioceptive, and motor efference) cues to guide movement. Environmental cues may be used to guide multiple navigation strategies that vary in complexity and flexibility. Beacon homing is rigid, dependent upon a single cue, but learned quickly, whereas piloting is more complex, using multiple cues, but is learned at a slower rate (Gallistel, 1990). When environmental cues are unfamiliar or access to them is restricted, self-movement cues may be used to update the current representation of the animal's position. This representation may be used to estimate the direction and distance to a former location, allowing the animal to plot a path to the point where movement originates; this is known as dead reckoning-based navigation (Darwin, 1873; Barlow, 1964; Mittelstaedt and Mittelstaedt, 1980). Dead reckoning is not dependent upon prior exposure and can be used independent of environmental cues; however, self-movement cues are not precise, and error accrues over time. Therefore, it is unlikely that an animal will depend upon a single source of information, and simultaneous use of environmental and self-movement cues will improve the ability to maintain spatial orientation.

The hippocampus (HPC) has been a focus of spatial research for decades. Electrophysiological and lesion studies have provided evidence for a role of the HPC in spatial processing (Tolman et al., 1946; O'Keefe and Dostrovsky, 1971; O’Keefe and Nadel, 1978; Morris et al., 1982; Sutherland et al., 1982); however, these studies do not dissociate environmental and self-movement cue processing. More recently, tasks have been developed that independently assess cue use. Performance on these tasks and their results are consistent with HPC lesions sparing the use of environmental cues while impairing use of self-movement cues (Maaswinkel et al., 1999; Gaffan et al., 2000). Although the activity of place cells is dependent upon location within the environment, self-movement cues have been shown to be sufficient to maintain place cell firing (Muller and Kubie, 1987; O'Keefe and Speakman, 1987; McNaughton et al., 1989; Quirk et al., 1990; Markus et al., 1994). These observations have led researchers to posit that the HPC is the site where distance and direction estimates are derived from self-movement cues (McNaughton et al., 1996; Whishaw, 1998; Wallace et al., 2008). HPC receives distance and direction 
information from two independent systems. First, hippocampal theta rhythm depends on projections from medial septum and is modulated by the distance associated with the initiation of subsequent movement (Whishaw and Vanderwolf, 1973; Winson, 1978; Oddie et al., 1997). Disruptions of these projections impair self-movement cue processing (Martin and Wallace, 2007; Martin et al., 2007, 2008). Second, head direction (HD) cells activate depending upon the directional bearing of the animal (Taube et al., 1990a,b). HD cells are located in serially connected regions that end at entorhinal cortex (EC), which projects into HPC. Lesions within various components of the HD circuit have found every region assessed to be involved in self-movement cue processing (Whishaw et al., 2001a; Parron and Save, 2004; Frohardt et al., 2006; Winter et al., 2011). HPC is positioned to receive distance and direction estimates (i.e., theta and $\mathrm{HD}$ cells) from regions implicated in processing self-movement cues, but it remains unknown how HPC transforms these two signals into a place representation.

The theta and HD cell signals converge not only on HPC but also on EC as well (Mitchell et al., 1982; McKinney et al., 1983; Mesulam et al., 1983; Woolf et al., 1984; Amaral and Witter, 1989; van Groen and Wyss, 1990; Caballero-Bleda and Witter, 1993, 1994). Neurons within EC exhibit theta activity (Mitchell and Ranck, 1980; Alonso and Garcia-Austt, 1987; Boeijinga and Lopes da Silva, 1988) and HD cell activity (Sargolini et al., 2006). In addition, grid cells have been discovered in EC that have multiple firing fields arranged in a triangular grid-like pattern (Fyhn et al., 2004; Hafting et al., 2005; Sargolini et al., 2006). The change in spacing between grid cell firing fields observed through the dorsal-ventral extent of EC has been posited to reflect a spatial metric or a distance estimation system (O'Keefe and Burgess, 2005; McNaughton et al., 2006; Hasselmo and Brandon, 2008; Moser and Moser, 2008). Individual neurons within EC have been found that have conjunctive representation of spatial information, such as HD plus grid cell properties (Sargolini et al., 2006). More recent work has demonstrated that manipulation of medial septum eliminates theta and grid characteristics while sparing HD characteristics of conjunctive cells (Brandon et al., 2011). The conjunctive representation of spatially tuned firing of individual neurons within EC indicates that it may be involved in the process of integrating distance and direction estimates at the neuron level. This process is important for dead reckoning; however, EC also receives input from visual cortex (Kerr et al., 2007). The exact role of EC in spatial processing remains unknown, but given the information it receives, it may be involved in environmental cue processing, self-movement cue processing, or both.

Previous work has demonstrated a role for self-movement cue processing in the organization of rat's spontaneously occurring exploratory behavior (Wallace et al., 2006). At a macrolevel of analysis, rats establish a home base and organize their movements around this location during the exploration of an environment (Eilam and Golani, 1989; Drai et al., 2000). In addition, movements away from the home base are typically slow and circuitous, whereas returns to the home base are fast and direct (Tchernichovski et al., 1998). A microlevel analysis has revealed that homeward segments are characterized by consistent temporal pacing of moment-to-moment speeds in which the peak speed typically occurs at the midpoint of the path (Wallace et al., 2006). Microlevel organization may be used to assess accuracy of direction and distance estimation. These aspects of exploratory trip organization are observed under light and dark conditions, consistent with a role for self-movement cue processing in estimating direction and distance to the home base. Although HPC lesions disrupt homeward segment organization under dark conditions, these lesions appear to spare some capacity to use environmental cues to guide movement on the homeward segment under light conditions (Wallace and Whishaw, 2003). The current study uses the spontaneous exploration task to evaluate the effects of HPC and EC lesions on self-movement cue-based direction and distance estimation. Observing that these lesions differentially influence exploratory trip organization will provide insight to the role of each structure in maintaining spatial orientation.

\section{METHODS}

\section{Animals}

Twenty-four female Long Evans rats (Rattus norvegicus) obtained from Northern Illinois University vivarium were pairhoused in plastic cages. The colony room was maintained at $\sim 20^{\circ} \mathrm{C}$ on a 12 -h light/dark cycle. Rats were $\sim 100$ days old at the beginning of the experiment. The NIU Institutional Animal Care and Use Committee, which follows the guidelines set forth by the Office of Laboratory Animal Welfare, approved all procedures used in this experiment.

\section{Surgery}

All rats were anesthetized with a mixture of isofluorane and oxygen during the surgery. Lesions of HPC $(n=6)$ were produced by injection of $0.40 \mu \mathrm{l}$ of $7.5 \mathrm{mg} N$-methyl-D-aspartic acid (Sigma, St. Louis, MO) in $1 \mathrm{ml}$ of saline at $0.20 \mu \mathrm{l} / \mathrm{min}$ into six lesion sites per hemisphere (see Table 1; Wallace and Whishaw, 2003). Sham-operated HPC rats $(n=6)$ were treated the same way except phosphate-buffered saline was infused. Lesions of EC $(n=6)$ were produced by passing anodal current of $\sim 2.0 \mathrm{~mA}$ for $10 \mathrm{~s}$ through an insulated electrode with $1 \mathrm{~mm}$ of the tip exposed. A total of 20 lesion sites per hemisphere were used (see Table 1). No coordinates are listed for the dorsal-ventral axis, because the electrode was lowered until it made contact with the base of the skull and then retracted $0.5 \mathrm{~mm}$ for the most ventral lesion site. The electrode was then retracted 0.4 $\mathrm{mm}$ between each subsequent site for a total of 10 lesion sites at each coordinate. We chose electrolytic lesions because of the high degree of specificity to one area and consistency in damage across rats. Pilot work using NMDA lesions produced high amounts of variability within and across rats and damage to 
TABLE 1.

\section{Stereotaxic Coordinates}

\begin{tabular}{lccc}
\hline Group & A-P & M-L & D-V \\
\hline HPC & -2.1 & \pm 2.0 & -3.6 \\
& -3.1 & \pm 3.0 & -3.5 \\
& -4.0 & \pm 3.5 & -3.5 \\
& -4.3 & \pm 5.2 & -5.5 \\
& -4.3 & \pm 5.2 & -7.5 \\
& -5.0 & \pm 5.0 & -7.3 \\
EC & -8.6 & \pm 5.7 & - \\
& -9.1 & \pm 5.2 & - \\
\hline
\end{tabular}

Coordinates relative to bregma.

surrounding structures. Previous behavioral studies often damaged surrounding structures (i.e., subicular regions, HPC), which is likely why they found conflicting results. We wanted to determine if there was any role for EC in processing environmental or self-movement cues independent of direct destruction of surrounding structures. This is why we damaged components throughout EC to assess for any possible effect, rather than focusing on select subcomponents, such as the dorsal-medial EC, which contains grid cells and HD cells. Although these electrophysiological signals provide compelling evidence for distinct processing within subcomponents of EC, the functional and behavioral role of these signals remains unknown. Sham-operated EC rats $(n=6)$ were treated the same way except the electrode was lowered, but no current was passed through. Spontaneous exploration began 1 week after surgery.

\section{Apparatus}

The apparatus was a wooden circular table $(200 \mathrm{~cm}$ in diameter) without walls that was painted white. It was mounted on top of a smaller circular table to allow easy rotation to displace odor cues. The surface of the table was $\sim 75 \mathrm{~cm}$ above the floor in a large room. A small box $(20 \times 29 \times 22 \mathrm{~cm})$ with a hole cut on the small side was placed along the edge of the table to be used as a refuge for the rats. The table was rotated and cleaned in between the testing sessions. A night-vision camera was positioned perpendicular to the surface of the table, and near-infrared light emitters were positioned along the periphery of the room. This allowed the testing room to be either illuminated using the normal fluorescent lighting or made complete dark and illuminated using near-infrared emitters, a spectrum of light rats cannot detect (Neitz and Jacobs, 1986).

\section{Procedure}

Rats were transported from the colony room to the testing room under complete dark conditions. During transportation, the cage was rotated, and the experimenter walked a circuitous path that varied across days to limit the rats' ability to learn the location of the testing room relative to the colony. Spontaneous exploration was conducted similar to methods described previously
(Whishaw et al., 2001a; Wallace and Whishaw, 2003; Wallace et al., 2006). In the current experiment, rats were tested first under dark conditions followed by light conditions. Changes in the order of testing conditions do not appear to influence control rat performance (i.e., light first: Whishaw et al., 2001a; Wallace and Whishaw, 2003; dark first: Wallace et al., 2006). It was decided in the current study to administer dark conditions first to limit exposure to nonvisual environmental cues and facilitate the use of self-movement cues. In addition, previous work has found that both testing under light conditions and HPC lesions independently increase the time a rat will spend inside the refuge and decrease exploration (Wallace and Whishaw, 2003). Therefore, under light conditions, the refuge was closed to foster exploration and ensure similar degrees of exposure to the lit environment during the time of exploratory trips.

A single exploratory session was $\sim 2$ h long during which a rat was placed inside the provided refuge and allowed to freely explore the environment. The refuge was always located along the perimeter of the table, and the refuge location was consistent for a single rat across testing days, but the location varied between rats. All rats were tested across multiple days until they had completed a minimum of eight exploratory trips. All behavioral testing was recorded for later off-line analysis. Exploratory trips were taken for analysis subsequent to home base establishment. Consistent with previous research, rats were considered to have established a home base when they completed a full body groom within or next to (i.e., under light conditions) the refuge (Eilam and Golani, 1989; Tchernichovski and Golani, 1995). A single exploratory trip was defined as a movement that took the rat away from the refuge and through the environment and ended with a continuous movement back to the refuge that began at least $75 \mathrm{~cm}$ away from the refuge. The first eight exploratory trips that met these criteria following home base establishment were included for analysis. Once a rat completed a minimum or eight exploratory trips under dark conditions, they were tested under light conditions.

\section{Data Analysis}

The EthoVision (Noldus, Leesburg, VA) motion capture system was used to quantify macrolevel movement characteristics of rats. Rats were tracked continuously for a $45-\mathrm{min}$ period of time during the testing session from which a majority of exploratory trips were sampled. Two measures were used to characterize the overall movement organization: Brown's scores (Brown and Whishaw, 2000) and total distance traveled. Brown's score was generated by dividing the exploration table into four equal quadrants and determining the amount of time spent in each quadrant. Brown's score was calculated by subtracting the percent time spent in the quadrants without a refuge $(\mathrm{Q} 1, \mathrm{Q} 2$, and $\mathrm{Q} 3)$ from the percent time spent in the quadrant with the refuge $(\mathrm{QR})$ and dividing by three $\{[(\mathrm{QR}-$ $\mathrm{Q} 1)+(\mathrm{QR}-\mathrm{Q} 2)+(\mathrm{QR}-\mathrm{Q} 3)] / 3\}$. This measure was used to quantify the amount of time spent in and around the refuge relative to the rest of the table to ensure home base establishment. Total distance traveled was calculated from the 
$x$ - and $y$-coordinates generated from the software. One-way ANOVAs with lesion (between-subjects) as a factor were conducted on both measures.

The peak performance (Vicon, Denver, CO) motion capture system was used to quantify microlevel movement characteristics of rats' individual exploratory trips. Movement was tracked by digitizing the pixel that corresponded to the midpoint between the forelimbs on every fifth frame. The resulting $x$ - and $y$-coordinates were scaled to real-world units and used to calculate the rats' location and moment-to-moment speeds. Exploratory trips were observed to be a series of linear progressions punctuated by stops (Wallace and Whishaw, 2003; Wallace et al., 2006). A stop was defined as the rat moving slower than $0.1 \mathrm{~m} / \mathrm{s}$ for $0.6 \mathrm{~s}$ or longer. Progressions were periods of continuous movement faster than 0.1 $\mathrm{m} / \mathrm{s}$. An exploratory trip was divided into outward and homeward segments. The outward segment was defined as all progressions and stops until the final stop. Outward segments varied in the number and length of progressions. Outward segment progressions were pooled across the eight trips and sorted into three categories: short, medium, and long. Two measures were used to characterize performance on the outward segment: circuity and peak error. Circuity was used for the outward segment to determine topographic characteristics. Circuity was calculated by dividing the distance between the start and end points of the progression by the total distance traveled on the progression. Circuity scores range from 0.0 to 1.0 with higher scores having more direct paths. Peak error was designed to assess the amount of deviation of the peak speed from the center of the progression. Previous work has found that rats modulate their peak speed on a moment-tomoment basis with the peak occurring approximately at the center for homeward progressions, but there is increased variability for outward progressions (Wallace and Whishaw, 2003; Wallace et al., 2006). Peak error was used here for the outward segment to determine kinematic characteristics. Peak error was calculated by subtracting the peak location (ranging from 0 to 1.0) from 0.5 (exact center) and taking the absolute value. Mixed design ANOVAs were conducted on each rat's average for each category with lesion (between-subjects) and length (within-subjects) as factors.

The homeward segment was defined as all movement that occurred after the final stop. Three measures were used to characterize performance on the homeward segment: circuity, heading error, and peak error. Circuity was calculated the same as outward segment circuity. Heading error was calculated as the angle subtended by the three points: beginning of the outward segment, beginning of the homeward segment, and location of the highest moment-to-moment speed on the homeward segment. Circuity and heading error are both topographic measures that relate to the rats' ability to estimate direction. Peak error was calculated the same as outward segment peak error. Peak error is a kinematic measure that relates to the rats' ability to estimate distance. One-way ANOVAs with lesion (betweensubjects) as a factor were conducted on all measures. To further characterize changes in performance, a follow-up analysis was conducted that compared homeward segments during dark and light exploration using a mixed design ANOVA with lesion (between-subjects) and test (within-subjects) as factors.

\section{Histology}

Subsequent to behavioral testing, rats were perfused through the heart, first with phosphate-buffered saline, then $4.0 \%$ paraformaldahyde. The brains were extracted and soaked for $24 \mathrm{~h}$ in $4.0 \%$ paraformaldahyde, followed by $24 \mathrm{~h}$ in $30 \%$ sucrose and distilled water. Brains were then frozen and sliced using a cryostat (Global Medical Instruments, Ramsey, MN). Rats from HPC and sham surgery groups had coronal sections taken, and rats from EC and sham surgery groups had horizontal sections taken. All sets were sliced at $50 \mu \mathrm{m}$ and processed for Cresyl violet to assess size and extent of the lesion.

\section{RESULTS}

No significant differences were found between HPC sham and EC sham groups on any measures of exploration. As a result, both groups were combined into a single sham group $(n=12)$. All lesion data are compared against this group.

\section{Histology}

Photomicrographs are presented for representative rats receiving HPC sham (Fig. 1A) or HPC lesion (Fig. 1B). Histological analysis of HPC lesion extent revealed extensive damage to the dorsal portion of the dentate gyrus and Ammon's horn. Damage within the ventral portion was less extensive with some sparing in most rats. HPC lesion size and extent was comparable to a previous study (Wallace and Whishaw, 2003). Photomicrographs are presented for representative rats receiving EC sham (Fig. 1C) or EC lesion (Fig. 1D). Histological analysis of EC lesion extent revealed restricted damage. Lesions were highly consistent across rats with damage focused on the border between the medial and lateral portions of EC. No lesion encroached upon presubiculum, parasubiculum, or HPC with damage stopping at alveus. Although the initial zone of damage around the electrolytic lesion was contained within the EC, it is possible that afferent projections were directly damaged resulting in plasticity in interconnected brain regions. Using a more selective lesion technique (i.e., NMDA) may spare direct damage of these afferents, but they are still likely to undergo plasticity due to the loss of their projection sites. Ventral portions of the lesion were restricted to EC, but dorsal portions encroached upon perirhinal cortex. EC Lesions did not encroach dorsally into retrosplenial or visual cortices. EC lesion size and extent were comparable to a previous study (Parron and Save, 2004).

\section{Dark Exploration}

Under dark conditions, general characteristics of exploratory behavior were equivalent among groups. Brown's scores did not vary among groups [sham: 0.625 (0.191); HPC: 0.492 (0.309); EC: $0.385(0.379)]$. The ANOVA conducted on Brown's scores failed to reveal a significant effect of group $\left[f_{(2,21)}=1.607, P\right.$ 

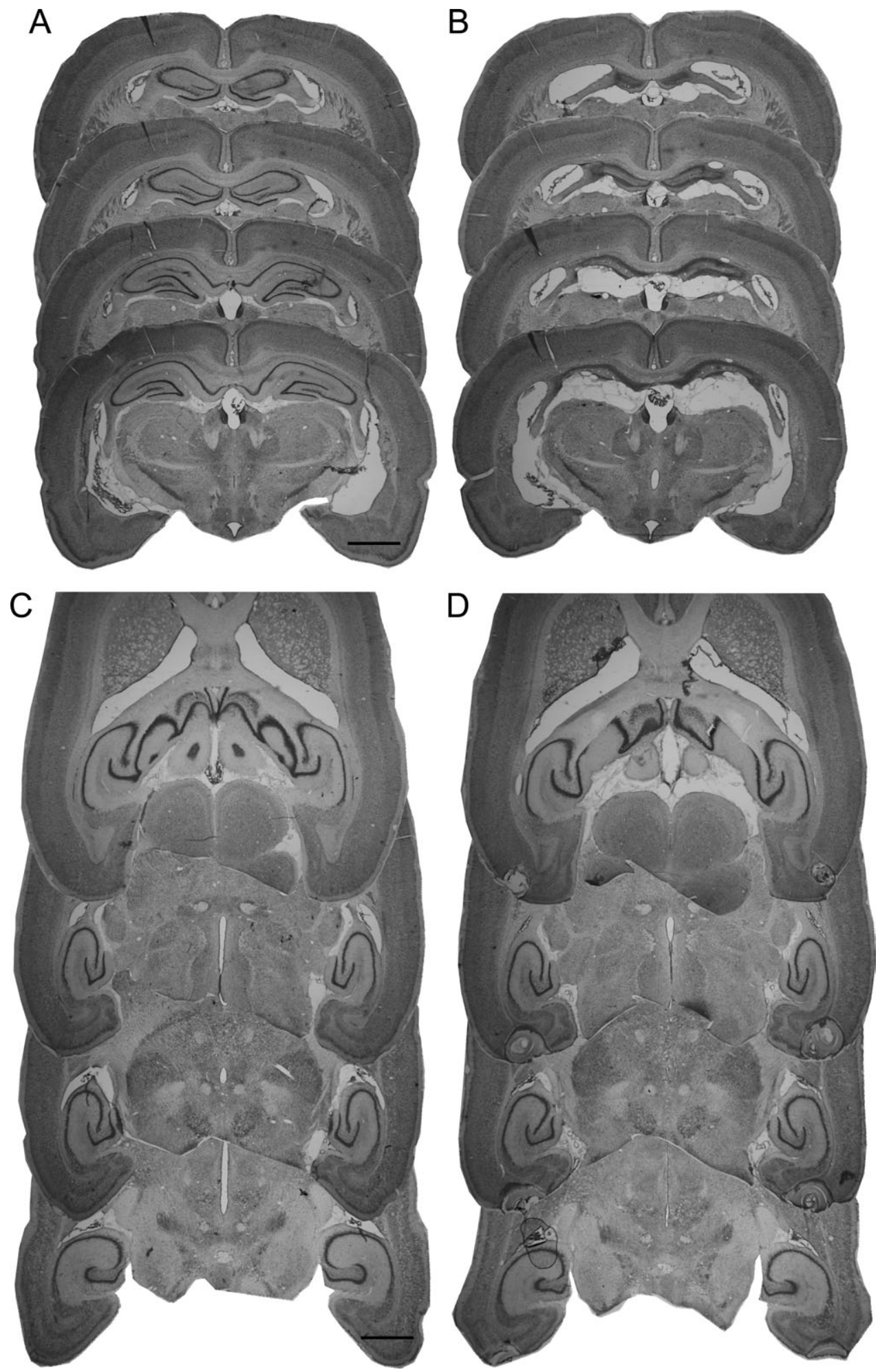

FIGURE 1. Photomicrographs of cresyl violet-stained coronal brain sections of sham and HPC (A and B) and horizontal sections of sham and EC (C and D) groups. HPC sections illustrate

$\left.=0.224, \eta_{\mathrm{p}}{ }^{2}=0.133\right]$. Total distance traveled did not vary among groups [sham: 187.3 (62.6); HPC: 189.9 (76.3); EC: 173.5 (29.7)]. The ANOVA conducted on total distance traveled failed to reveal a significant effect of group $\left[f_{(2,21)}=\right.$

the dorsal HPC from anterior-posterior (top-bottom), and EC sections illustrate from dorsal-ventral (top-bottom). Scale bar: $2 \mathrm{~mm}$.

0.137, $P=0.873, \eta_{\mathrm{p}}{ }^{2}=0.013$ ]. Groups did not significantly differ in macrolevel organization of exploratory behavior.

Group differences were observed at the level of exploratory trip organization (see Fig. 2A). Outward progression topographic 
A

SHAM

HPC

EC
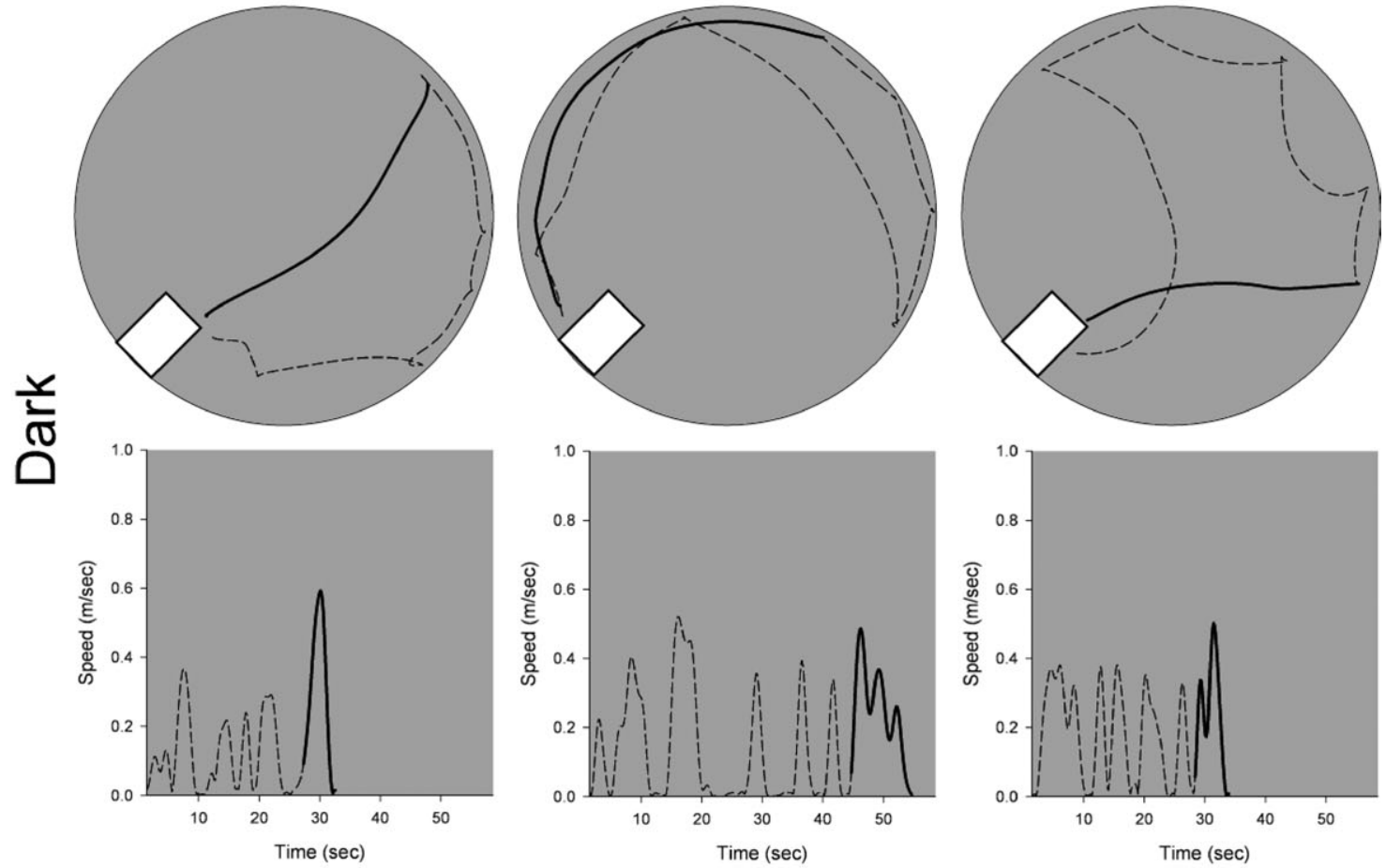

B
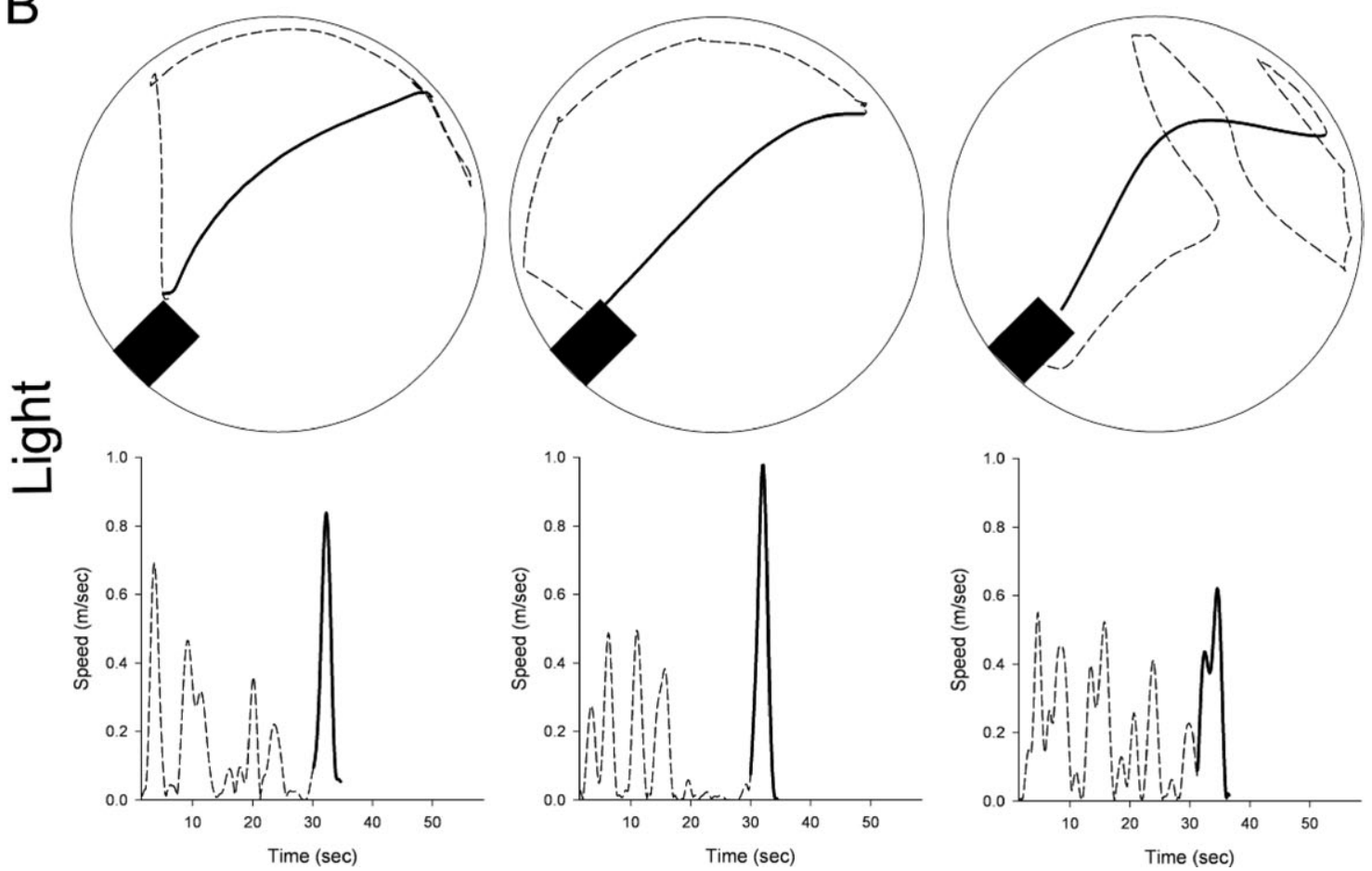

FIGURE 2. Dark (A) and light (B) exploration topographic (top) and kinematic (bottom) plots for a single representative exploratory trip's outward (dashed) and homeward (solid) progressions from sham (left), HPC (middle), and EC (right) groups.

characteristics varied as a function of progression length and group. The ANOVA conducted on circuity (see gray panel of Fig. 3A) revealed a significant main effect of length $\left[f_{(2,42)}=\right.$ 41.561, $\left.P<0.001, \eta_{\mathrm{p}}{ }^{2}=0.664\right]$, and length $\times$ group interaction $\left[f_{(4,42)}=3.373, P=0.018, \eta_{\mathrm{p}}{ }^{2}=0.243\right]$, but no significant main effect of group $\left[f_{(2,21)}=2.509, P=0.105, \eta_{\mathrm{p}}{ }^{2}=0.193\right]$. Post hoc analysis revealed a significant linear trend $\left[f_{(1,21)}=\right.$ 57.247, $\left.P<0.001, \eta_{\mathrm{p}}{ }^{2}=0.732\right]$ in path circuity, in which paths became more circuitous from short to long progressions. In addition, the HPC group had more circuitous long progressions rela- 

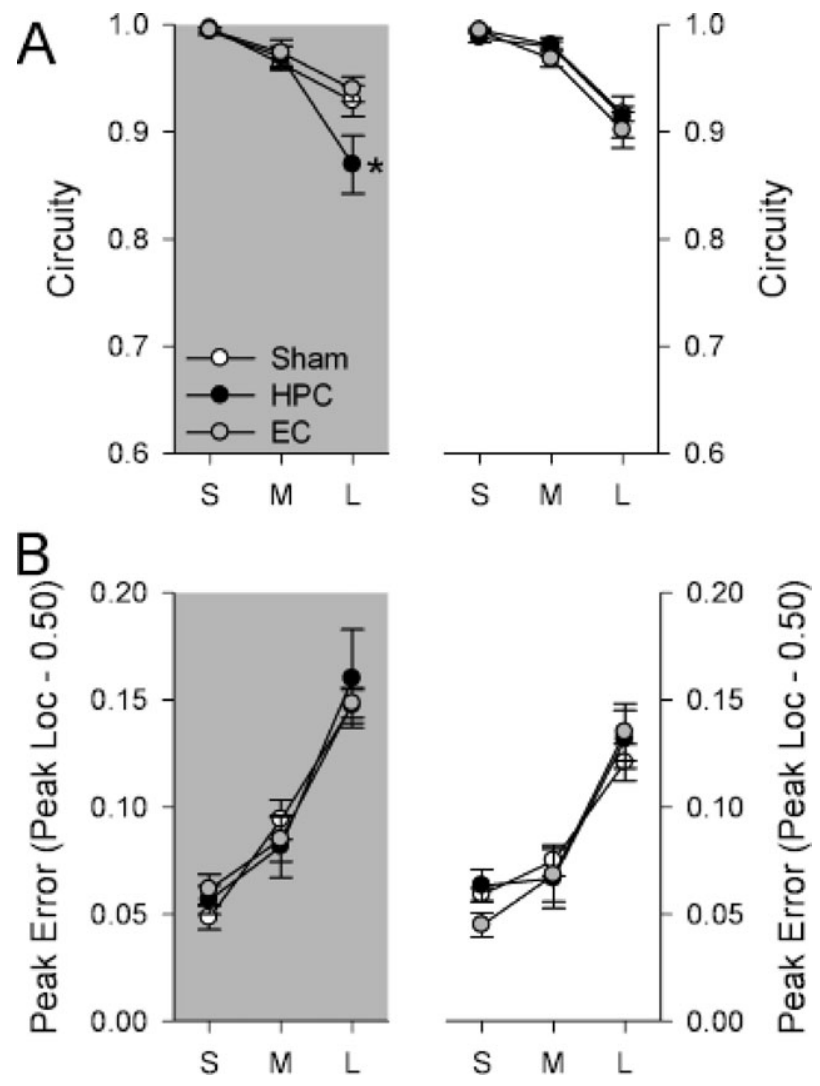

FIGURE 3. Plots of outward progression circuity (A) and peak error (B) for dark (gray) and light (white) exploration. Asterisks indicate group differences.

tive to sham or EC (LSD; $P<0.050$ ), but there were no differences between groups for short or medium progressions.

Outward progression kinematic characteristics varied as a function of length but not group. The ANOVA conducted on outward progression peak errors (see gray panel of Fig. 3B) revealed a significant main effect of length $\left[f_{(2,42)}=69.302\right.$, $\left.P<0.001, \eta_{\mathrm{p}}^{2}=0.767\right]$, but no significant main effect of group $\left[f_{(2,21)}=0.026, P=0.975, \eta_{\mathrm{p}}^{2}=0.002\right]$ or length $\times$ group interaction $\left[f_{(4,42)}=0.758, P=0.558, \eta_{\mathrm{p}}{ }^{2}=0.067\right]$, indicating that groups did not significantly differ in outward segment kinematics. Post hoc analysis on the main effect of length revealed a significant linear trend $\left[f_{(1,21)}=154.151\right.$, $\left.P<0.001, \eta_{\mathrm{p}}^{2}=0.880\right]$, indicating that kinematic variability increased with longer outward progressions. Overall, groups did not differ in the organization of topography or kinematics of their outward segment.

Homeward progression topographic characteristics differed across groups. The ANOVA conducted on circuity (see gray panel of Fig. 4A) revealed a significant main effect of group $\left[f_{(2,21)}=34.466, P<0.001, \eta_{\mathrm{p}}^{2}=0.766\right]$. Post hoc analysis revealed the HPC group to have significantly more circuitous paths than either sham or EC (LSD; $P<0.001$ ), which did not differ significantly from each other (LSD; $P=0.812$ ). The ANOVA conducted on heading error (see gray panel of Fig. 4B) revealed a significant main effect of group $\left[f_{(2,21)}=\right.$
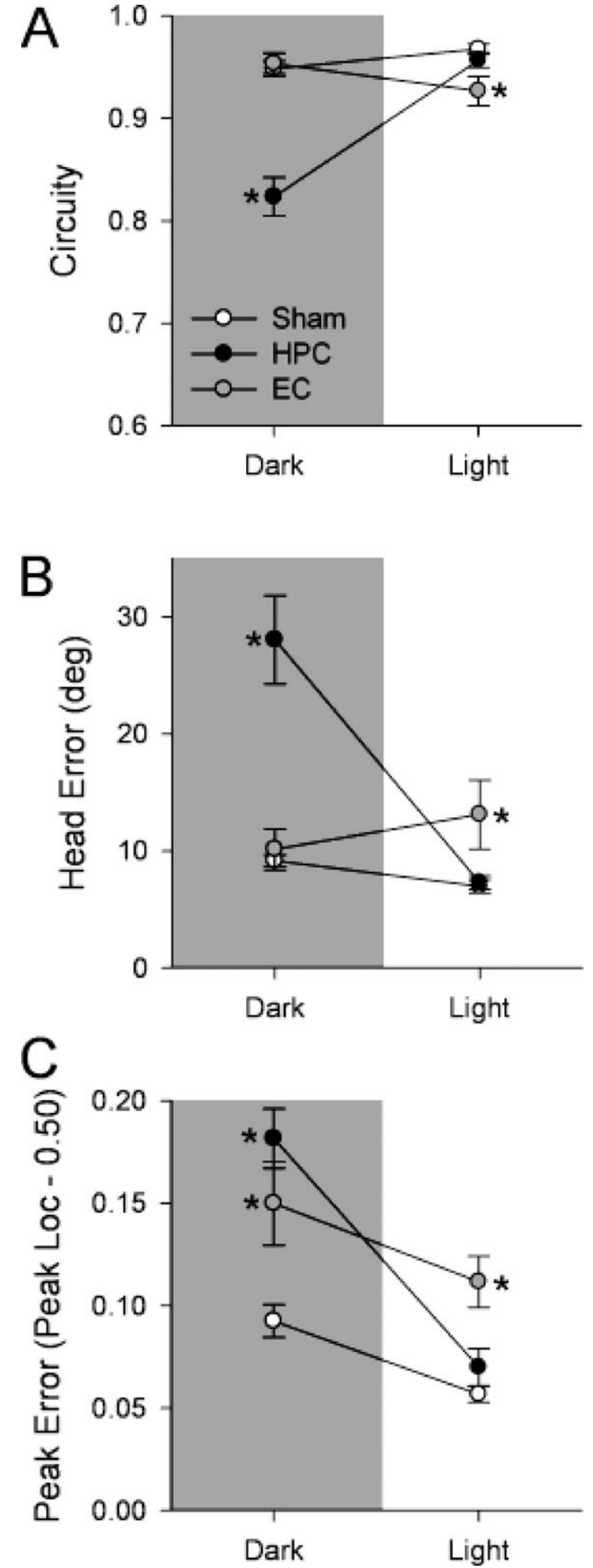

FIGURE 4. Plots of homeward progression circuity (A), heading error (B), and peak error (C) comparing dark (gray) and light (white) exploration. Asterisks indicate group differences.

29.681, $\left.P<0.001, \eta_{\mathrm{p}}{ }^{2}=0.739\right]$. Post hoc analysis revealed the HPC group to have significantly larger heading error than either sham or EC (LSD; $P<0.001)$, which did not differ significantly from each other (LSD; $P=0.708$ ). 
Homeward progression kinematic characteristics differed across groups. The ANOVA conducted on peak error (see gray panel of Fig. 4C) revealed a significant main effect of group $\left[f_{(2,21)}=14.611, P<0.001, \eta_{\mathrm{p}}{ }^{2}=0.582\right]$. Post hoc analysis revealed HPC, and EC groups had significantly larger peak error than sham (LSD; $P<0.003$ ), but HPC and EC did not differ from each other (LSD; $P=0.136$ ). Lesions of HPC affected both topography and kinematics, but lesions of EC affected only kinematics when rats were restricted to self-movement cues.

\section{Light Exploration}

Under light condition, general characteristics of exploratory behavior were equivalent among groups. Brown's scores did not vary among groups [sham: 0.730 (0.382); HPC: 0.849 (0.037); EC: $0.488(0.414)]$. The ANOVA conducted on Brown's scores failed to reveal a significant effect of group $\left[f_{(2,21)}=1.762, P=\right.$ $\left.0.196, \eta_{\mathrm{p}}{ }^{2}=0.144\right]$. Total distance traveled did not vary among groups [sham: 107.7 (46.6); HPC: 103.8 (57.9); EC: 121.1 (31.4)]. The ANOVA conducted on total distance traveled failed to reveal a significant effect of group $\left[f_{(2,21)}=0.238, P=\right.$ $\left.0.790, \eta_{\mathrm{p}}{ }^{2}=0.022\right]$. Groups did not significantly differ in the macrolevel organization of exploratory behavior.

Group differences were observed at the level of exploratory trip organization (see Fig. 2B). Outward progression topographic characteristics varied as a function of progression length, but not group. The ANOVA conducted on circuity (see white panel of Fig. 3A) revealed a significant main effect of length $\left[f_{(2,42)}=\right.$ 85.936, $\left.P<0.001, \eta_{\mathrm{p}}{ }^{2}=0.804\right]$, but there was no significant main effect of group $\left[f_{(2,21)}=0.969, P=0.396, \eta_{\mathrm{p}}{ }^{2}=0.084\right]$ or length $\times$ group interaction $\left[f_{(4,42)}=0.410, P=0.800, \eta_{\mathrm{p}}{ }^{2}\right.$ $=0.038]$. Post hoc analysis on the main effect of length revealed a significant linear trend $\left[f_{(1,21)}=124.192, P<0.001\right.$, $\left.\eta_{\mathrm{p}}{ }^{2}=0.855\right]$, indicating that topography became more circuitous with longer outward progressions.

Outward progression kinematic characteristics varied as a function of length, but not group. The ANOVA conducted on peak error (see white panel of Fig. 3B) revealed a significant main effect of length $\left[f_{(2,42)}=54.680, P<0.001, \eta_{\mathrm{p}}{ }^{2}=0.723\right]$, but there was no significant main effect of group $\left[f_{(2,21)}=0.097, P=\right.$ $\left.0.908, \eta_{\mathrm{p}}{ }^{2}=0.009\right]$ or length $\times$ group interaction $\left[f_{(4,42)}=\right.$ $0.950, P=0.445, \eta_{\mathrm{p}}{ }^{2}=0.083$ ], indicating that groups did not significantly differ in outward segment kinematics. Post hoc analysis on the main effect of length revealed a significant linear trend $\left[f_{(1,21)}=78.709, P<0.001, \eta_{\mathrm{p}}{ }^{2}=0.789\right]$, indicating that kinematic variability increased with longer outward progressions. Groups did not differ in the organization of topography or kinematics of their outward segment.

Homeward segment topographic characteristics differed across groups. The ANOVA conducted on circuity (see white panel of Fig. 4A) revealed a significant main effect of group $\left[f_{(2,21)}=6.968, P=0.005, \eta_{\mathrm{p}}{ }^{2}=0.399\right]$. Post hoc analysis revealed the EC group to have significantly more circuitous paths than either sham or HPC (LSD; $P<0.05$ ), which did not differ significantly from each other (LSD; $P=0.394)$. The
ANOVA conducted on heading error (see white panel of Fig. $4 \mathrm{~B})$ revealed a significant main effect of group $\left[f_{(2,21)}=5.547\right.$, $\left.P=0.012, \eta_{\mathrm{p}}{ }^{2}=0.346\right]$. Post hoc analysis found the EC group to have significantly higher heading error than either sham or HPC (LSD; $P<0.050$ ), which did not differ significantly from each other (LSD; $P=0.868$ ).

Homeward progression kinematic characteristics differed across groups. The ANOVA conducted on peak error (see white panel of Fig. 4C) revealed a significant main effect of group $\left[f_{(2,21)}=13.935, P<0.001, \eta_{\mathrm{p}}{ }^{2}=0.570\right]$. Post hoc analysis found the EC group to have significantly higher peak error than either sham or HPC (LSD; $P<0.050$ ), which did not differ significantly from each other (LSD; $P=0.232$ ). Lesions of HPC spared topography and kinematics, but lesions of EC impaired both topography and kinematics when environment and self-movement cues were accessible.

\section{Comparison of Dark and Light Exploration}

Groups differed in the way topographic and kinematic characteristics changed from dark to light conditions. The ANOVA conducted on circuity (see Fig. 4A) revealed a significant main effect of test $\left[f_{(1,21)}=19.091, P<0.001, \eta_{\mathrm{p}}{ }^{2}=0.479\right]$, group $\left[f_{(2,21)}=36.841, P<0.001, \eta_{\mathrm{p}}{ }^{2}=0.778\right]$, and test $\times$ group interaction $\left[f_{(2,21)}=20.371, P<0.001, \eta_{\mathrm{p}}{ }^{2}=0.660\right]$. For post hoc analysis, each group was analyzed separately to determine the change in movement characteristics across dark and light homeward progressions. Post hoc analysis revealed that the HPC group made more direct homeward progressions under light than dark exploration (LSD; $P<0.050$ ), but there was no change for sham or EC (LSD; $P>0.050$ ). The ANOVA conducted on heading error (see Fig. 4B) revealed a significant main effect of test $\left[f_{(1,21)}=17.961, P<0.001, \eta_{\mathrm{p}}{ }^{2}=0.461\right]$, group $\left[f_{(2,21)}=25.814, P<0.001, \eta_{\mathrm{p}}{ }^{2}=0.711\right]$, and test $\times$ group interaction $\left[f_{(2,21)}=18.371, P<0.001, \eta_{\mathrm{p}}{ }^{2}=0.636\right]$. Post hoc analysis revealed heading error to be significantly lower under light than dark exploration for sham and HPC (LSD; $P$ $<0.050$ ), but not for EC (LSD; $P>0.050$ ). The ANOVA conducted on peak error (see Fig. 4C) revealed a significant main effect of test $\left[f_{(1,21)}=42.399, P<0.001, \eta_{\mathrm{p}}{ }^{2}=0.669\right]$, group $\left[f_{(2,21)}=25.868, P<0.001, \eta_{\mathrm{p}}{ }^{2}=0.711\right]$, and test $\times$ group interaction $\left[f_{(2,21)}=6.538, P=0.006, \eta_{\mathrm{p}}{ }^{2}=0.384\right]$. Post hoc analysis revealed peak error to be significantly lower under light than dark exploration for sham and HPC (LSD; $P$ $<0.050$ ), but not for EC (LSD; $P>0.050$ ). Both sham and HPC groups' performance improved from dark to light conditions, but the EC group's performance did not change.

\section{DISCUSSION}

Although macrolevel aspects of exploratory behavior did not vary among groups, HPC and EC lesions differentially influenced microlevel exploratory trip organization. First, HPC lesions disrupted topographic and kinematic characteristics of 
the homeward segment under dark conditions, but spared these characteristics under light conditions. Second, EC lesions disrupted kinematic characteristics of the homeward segment under light and dark conditions, whereas topographic characteristics were spared under dark conditions only. These results provide evidence for a critical role of HPC in the integration of selfmovement cues and the involvement of EC in distance estimation through the use of environmental or self-movement cues.

\section{Spontaneous Exploration as a Complex Spatial Task}

Spontaneous exploration is a naturalistic task that takes advantage of different levels of organization inherent in rodent behavior. Macrolevel characteristics relate to the overall organization of the rats' behavior within their environment and may be used to make inferences about motor function, motivation, etc. At the macrolevel, when allowed to freely explore an open environment, rats organize their behavior around a central location called a home base (Eilam and Golani, 1989; Tchernichovski and Golani, 1995; Wallace and Whishaw, 2003). Rats spend a high percentage of time around the home base and have increased grooming and rearing at this location. Exploratory trips are initially within close proximity to the home base and increase in distance over time (Tchernichovski et al., 1998). Microlevel characteristics relate to the organization of individual movements and may be used to make inferences about specific aspects of spatial information processing such as distance or direction estimation. At the microlevel, exploratory trips are a series of linear progressions punctuated by stops with the final progression returning the rat to the home base. Relative to outward progressions of equal length, homeward progressions are characterized by relatively low path circuity, high peak speed, and consistent temporal pacing of moment-to-moment speeds (Eilam and Golani, 1989; Tchernichovski and Golani, 1995; Wallace and Whishaw, 2003; Wallace et al., 2006). Microlevel characteristics of movement organization can be divided into topographic measures related to orientation and direction estimation and kinematic measures related to moment-tomoment speed modulation and distance estimation. Microlevel exploratory trip organization has been observed under light and dark testing conditions (Whishaw et al., 2001a; Wallace and Whishaw, 2003; Wallace et al., 2006). Exploring under dark conditions restricts access to self-movement and nonvisual environmental cues, whereas light conditions allow access to all cues from the environment and those generated from self-motion.

Under dark conditions, it is unlikely that rats rely upon olfactory cues, because they make multiple circuitous exploratory trips that limit the reliability of olfactory cues. When rats scenttrack, they display a platykurtic kinematic profile, but during homeward progressions in spontaneous exploration, they have a leptokurtic kinematic profile (Wallace and Whishaw, 2003). The kinematic profile when reliant upon olfaction differs significantly from the kinematic profile of a homeward progression guided by either self-movement or visual cues. The same leptokurtic profile has been observed during visually and nonvisually guided reaching with humans, suggesting that these movements are a ballistic sequence of motor commands (Morasso, 1981; Gordon et al., 1994). In contrast, outward progressions of equivalent length to homeward progressions exhibit less consistency in their kinematic profile (Wallace and Whishaw, 2003; Wallace et al., 2006). These results indicate that the homeward progression is a unique component of an exploratory trip that is calculated rather than the consequence of a biomechanical system. In addition, the behavioral measures from spontaneous exploration across dark and light conditions are comparable that allows for direct comparison of processing accuracy between visual and self-movement cues. The focus of the current study was to use the selectivity of microlevel analysis of spontaneous exploration to further characterize the role of limbic system structures in spatial information processing. The following sections will discuss the effect of limbic system lesions upon microlevel characteristics of movement organization and the implications of these findings upon information processing through the limbic system.

\section{Limbic System Lesions Differentially Disrupt Exploratory Trip Organization}

The contribution of HPC in spatial orientation continues to be debated [(Bohbot et al., 1998; Philbeck et al., 2004; Wolber et al., 2007); however, see Jeneson and Squire (2011)]. Although traditional views posit its role as a cognitive map (O'Keefe and Nadel, 1978), there is a growing body of literature supporting a role for HPC in processing self-movement cues. In addition, HPC receives independent streams of information from limbic structures involved in processing self-movement cues (Parron and Save, 2004; Frohardt et al., 2006; Martin and Wallace, 2007; Winter et al., 2011). HPC is positioned to integrate these streams of information for the process of dead reckoning. Results from the current experiment provide further evidence that HPC is necessary for accurate integration of self-movement cues.

Lesions of HPC selectively influenced the homeward segment of exploratory trips. First, the overall organization of exploratory behavior was not influenced by lesions of HPC under either testing condition. All rats established a home base in the refuge provided. Macrolevel movement characteristics further support that all rats organized their behavior around the refuge and traveled equivalent amounts. Microlevel movement characteristics for the outward segment were generally spared following HPC lesions. Under light conditions, HPC lesions spared outward segment circuity and peak error; however, under dark conditions, they spared outward segment peak error but influenced circuity. HPC lesions resulted in more circuitous long outward progressions but not short or medium progressions. This may be the result of increased thigmotaxic behavior under dark conditions, a compensatory strategy used due to impaired self-movement cue processing (see below). Thigmotaxic long progressions are more circuitous than direct long progressions. In addition, under light conditions, when HPC lesion rats no longer used a thigmotaxic strategy to return to the refuge, they no longer exhibited an increase in long outward progression circuity. Overall, HPC 
lesions spared outward segment movement characteristics. Second, under dark conditions, HPC lesions disrupted homeward progression topography and kinematics. Dark conditions restrict access from visual cues, so that rats must rely upon self-movement cues or other environmental cues such as olfaction. It is unlikely that HPC lesion rats relied upon olfactory cues as they had a unique kinematic profile with multiple peaks during a single homeward progression rather than the platykurtic kinematic profile characteristic of scent-tracking. These results indicate that under dark conditions, rats primarily rely upon self-movement cues to return to the refuge and lesions of HPC disrupt the ability to modulate moment-to-moment speed. HPC lesions disrupted homeward topography resulting in circuitous routes along the periphery of the table. Use of a thigmotaxic strategy is likely the result of the lesion rats' inability to process self-movement cues to accurately orient toward the refuge. Lesions of HPC disrupted topographic and kinematic characteristics indicating impaired ability to process self-movement cues to estimate distance or direction. Finally, under light conditions, HPC lesions spared homeward segment topography and kinematics. Lesion rats' performance was equivalent to shams under light conditions, and they significantly improved from dark to light conditions. When given access to visual cues, HPC lesion rats generated accurate direction and distance estimates. These rats maintained the ability to orient accurately and modulate their moment-to-moment speed, but only when given access to visual cues. Performance during spontaneous exploration provides evidence that HPC lesions selectively impair dead reckoning while sparing the ability to use environmental cues to maintain orientation. Behavioral evidence from the current study supports a role for HPC in the integration of self-movement cues.

Subcortical limbic structures that project into HPC also project into EC, such as medial septum, along with other regions involved in processing self-movement cues (Mitchell et al., 1982; McKinney et al., 1983; Mesulam et al., 1983; Woolf et al., 1984; van Groen and Wyss, 1990). In addition, EC receives input from visual regions (Kerr et al., 2007). Electrophysiological studies have found multiple spatially tuned cells (i.e., theta, HD, and grid cells) that led to the development of computational models positing a role for EC in dead reckoning (O'Keefe and Burgess, 2005; McNaughton et al., 2006; Hasselmo and Brandon, 2008; Moser and Moser, 2008). Despite these two lines of evidence, behavioral work has not been done that clearly illustrates the role of EC. Lesion studies have produced mixed results on traditional spatial tasks that do not dissociate environmental and self-movement cues (Galani et al., 1997; Kesner and Giles, 1998; Galani et al., 2002; Parron and Save, 2004; Parron et al., 2004; Steffenach et al., 2005). When tested in the food-hoarding task, EC lesions impaired selfmovement cue use; unfortunately, environmental cue use was not assessed (Parron and Save, 2004). The current study builds upon these results by assessing self-movement and environmental cue processing and provides evidence that it plays a role in processing both sources of cues.

Lesions of EC selectively influenced the homeward progression of exploratory trips. In general, the nature of the impairments did not depend upon the source of spatial information as distance estimation was impaired across conditions. First, the overall organization of exploratory behavior was not influenced by lesions of EC under either testing conditions. All rats established a home base in the refuge provided. Macrolevel movement characteristics further support that all rats organized their behavior around the refuge and traveled equivalent amounts. Microlevel movement characteristics of topography and kinematics of the outward segment were spared. EC lesions spared outward segment circuity and peak error during dark and light exploration. Second, under dark conditions, EC lesions disrupted homeward progression kinematics but spared topography. Lesion rats maintained the ability to orient accurately toward the refuge; however, they were impaired in the ability to modulate their speed on a moment-to-moment basis. Spared ability to estimate direction following EC lesions is not surprising, given that EC lesions spare HD cell activity in anterodorsal thalamus (Clark and Taube, 2011). Although EC contains HD cells, their function does not play a critical role in direction estimation when reliant upon self-movement cues. Alternatively, the current EC lesions were not complete, and there may be spared HD cells that allowed for the spared ability to estimate direction. Control rats modulate their speed during homeward progressions, so that they have a leptokurtic kinematic profile with the peak in speed occurring at the center independent of the length of the progression. EC lesion rats have an increased peak error, meaning more variability of the peak speed location from the center of the homeward progression. They do not modulate their speed within a progression dependent upon the length of that progression, indicating impairment in their ability to estimate distance. Lesions of EC resulted in spared topography but impaired kinematics indicating intact direction estimation but impaired distance estimation when reliant upon self-movement cues. Finally, under light conditions, EC lesions disrupt homeward progression topographic and kinematic characteristics. Although light exploration provides access to environmental and self-movement cues, EC lesion rats were limited in their ability to use either source of information to improve the accuracy of the homeward segment from dark to light conditions. Sham rats improved the accuracy of their orientation from dark to light conditions indicating visual cues aids performance. In contrast, EC lesion rats' performance did not significantly change from dark to light conditions indicating impairment in their ability to use visual cues to aid performance. Although there was no significant change, their performance under light conditions was marginally lower and had more variability. This suggests that access to visual cues may have caused some nonsignificant reduction in performance accuracy. Future studies should investigate this at the microlevel through manipulation of distal cues to determine if they had any consistent impact upon EC lesion rats' performance. Overall, this pattern of results indicates that providing access to visual cues does not disrupt the performance of EC lesion rats as much as it fails to improve performance under light conditions. The performance of EC rats observed under both conditions is consistent with EC lesions impairing 
an ability to use either source of information to estimate distance and use environmental cues to compensate for this impaired processing.

\section{Neurobiology of Self-Movement Cue Processing}

Development of a model of spatial orientation is dependent upon understanding the neural systems that contribute to selfmovement cue processing, because these cues are the foundation of spatial orientation. Self-movement cues are reliable within a novel environment before learning the associations necessary for environmental cue use. Disruption of self-movement cues attenuates learning associations between environmental cues (Semenov and Bures, 1989; Biegler and Morris, 1996). Use of self-movement cues requires an animal to monitor linear and angular changes over time and continuously integrate these changes to estimate its distance and direction to a previous location. Two lines of evidence suggest that distance and direction are dissociable components of spatial processing. First, behavioral experiments with hamsters have shown their ability to compensate for angular but not linear displacement during passive transport (Etienne et al., 1986). In addition, behavioral experiments with rats and humans in the Morris water task have shown sequential control of performance by distal and proximal cues [for review, see Knierim and Hamilton (2011)]. The authors argue that initial orientation (direction estimation) is generated from distal cues, and precise platform location (distance estimation) is generated from proximal cues. Although these studies are not restrictive to self-movement cue use, they do demonstrate the ability for direction and distance estimates to be generated from separate sources, suggesting independent streams of processing. Second, electrophysiological studies have discovered spatially tuned cellular activation within select regions of the brain. Theta rhythm is modulated by distance associated with the initiation of subsequent movement [(Whishaw and Vanderwolf, 1973); for review, see Vertes et al. (2004)], whereas, HD cells activate dependent upon the orientation of an animal's head in space [for review, see Taube (2007)]. Both theta and HD cell firing are generated within subcortical structures and are present in multiple brain regions that eventually terminate in the cortex and HPC. Interestingly, these circuits appear to inhabit many of the same structures but are contained within segregated nuclei in each structure. For example, both circuits have been found in the tegmental nuclei, mammillary bodies, anterior thalamus, retrosplenial cortex, subiculum, and EC (Vertes et al., 2004; Taube, 2007). This suggests that there are two independent pathways for processing distance (theta) and direction (HD cells) estimates generated from self-movement cues, and these signals converge upon HPC. Although recent reviews have posited a role for structures outside of the HPC as mediating self-movement cue processing (Hasselmo and Brandon, 2008; Kubie and Fenton, 2009; Knierim and Hamilton, 2011), results of the current study do not support their predictions. Only lesions of HPC disrupted direction and distance estimation when dependent upon self-movement cues, replicating previous findings
(Wallace and Whishaw, 2003). EC lesions only disrupted distance estimation when dependent upon self-movement cues, suggesting that HD cells outside the lesioned area maintained behavioral control. These results provide the first evidence of a selective deficit in distance estimation, indicating that a possible behavioral double dissociation may be found between the distance and direction signals that converge upon HPC.

A behavioral double dissociation between HD cells and the theta signal has been proposed previously [for review, see Wallace et al. (2008)]; however, lesions within these systems have failed to produce selective deficits in direction and distance estimation. One possible reason that no behavioral dissociation has been reported between these two signals is the anatomical layout of this circuit. Both theta and HD cells get processed within parallel structures and converge upon HPC. The structures that comprise this circuit can be divided into two categories: subcortical and cortical. Subcortical structures are thought to be involved in the generation of the signals largely through self-movement cues, and distance and direction remain segregated from one another within the subcortical structures. Cortical structures are thought to provide higher level processing and integration with environmental information, and there is a convergence of distance and direction within the cortical structures. To investigate the neural correlates of self-movement cue processing, our laboratory has damaged the subcortical components (i.e., medial septum and mammillothalamic tract) of this circuit (Martin and Wallace, 2007; Winter et al., 2011). Both these studies found impairments when rats were restricted to using self-movement cues; however, the food-hoarding task is limited in its ability to dissociate distance and direction estimation. The current study used a more refined analysis during a spontaneous exploration task that allows for independent assessment of distance and direction estimation. Lesions of EC produced selective impairments in kinematic but spared topographic characteristics during dark exploration. These results provide evidence for a selective deficit in distance estimation following lesions of EC. There are several possible explanations for why EC is the first region in which we have found selective impairments in one component of self-movement cue processing. First, the ability to accurately estimate one component (i.e., distance or direction) may depend upon both components. For example, monitoring linear changes over time may provide the total distance traveled, but it is not informative of distance from a previous location without monitoring of directional changes as well. Therefore, disruption of subcortical systems involved in the generation of the signal for either component may completely eliminate that signal and impair the integration and subsequent estimation of the other. Second, producing a selective deficit in distance estimation following EC damage may be due to decreased but not complete loss of the distance signal. EC lesions may decrease the accuracy of distance estimates resulting in behavioral impairments during the exploration task; however, sufficient distance information may be spared within the system to allow the directional signal to function accurately. Other cortical systems interconnected with EC and HPC may be able to partially compensate for the 
loss of distance information. For example, the subicular cortex is connected with EC and HPC (Amaral and Witter, 1989; van Groen and Wyss, 1990; Caballero-Bleda and Witter, 1993, 1994), and this region exhibits theta, HD cell, and grid cell activity (Taube et al., 1990a,b; Cacucci et al., 2004; Glasgow and Chapman, 2007; Boccara et al., 2010). The subicular cortex may have been able to compensate for the decrement in the distance signal enough to maintain accurate direction estimation but insufficient to maintain behavioral control of distance estimation. This leads us to predict that damage within cortical structures that are preferentially involved in direction processing may produce selective behavioral impairments in direction estimation. The retrosplenial cortex exhibits HD cells (Chen et al., 1994a,b; Cho and Sharp, 2001) and theta (Talk et al., 2004) but lacks grid cells, suggesting that it may play a preferential role in direction estimation. Lesions of the retrosplenial cortex impair environmental [(Harker and Whishaw, 2002, 2004; however, see Neave et al. (1994) and Aggleton et al. (1995)] and self-movement (Whishaw et al., 2001b) cue processing; however, the tasks used in these studies did not evaluate distance and direction processing independently. Lesions of the retrosplenial cortex exhibit the same pattern of results exhibited by EC lesions in the current study. Future studies need to be done to determine if the retrosplenial cortex produces a selective behavioral impairment in direction estimation when dependent upon self-movement cues.

One final note is that the current study used only female rats. There is evidence of sexually dimorphic performance on spatial tasks across multiple species [for review, see Jones et al. (2003)]; however, many spatial tasks have multiple strategies that can be used to complete the task. Sexually dimorphic performance may be the result of strategy selection and utilization rather than spatial information processing. Köppen et al. (In Press) recently found sex difference between male and female rats in the Morris water task on traditional measures (i.e., latency and distance), but they failed to find significant sex differences in novel measures of spatial processing during training and performance during probes. These results indicate that initial strategy selection between male and females may be driving performance differences, but spatial information process is equivalent. Sex differences of microlevel analysis of spatial information processing have not been conducted. Tchernichovski and Golani (1995) used male and female rats but made no reference to differences in performance; however, sex differences were not directly assessed. Future studies need to be conducted to assess sexually dimorphic spatial information processing at the microlevel.

\section{CONCLUSION}

This study examined HPC and EC involvement in selfmovement and environmental cue processing. HPC lesions selectively impaired self-movement cue but spared environmental cue processing, which is consistent with the previous behavioral work. This result provides additional evidence that HPC is involved in integrating direction and distance estimates derived from self-movement cues. EC lesions impaired distance estimation independent of cue availability and impaired environmental cue processing. These results are in conflict with predictions of EC function generated by computational models that attempt to explain firing characteristics of single cells within EC. These models suggest that EC is involved in distance estimation from self-movement cues. These observations demonstrate the importance of behavioral experiments and independent assessment of self-movement and environmental cue processing in conjunction with electrophysiological studies.

\section{Acknowledgments}

The authors thank Lindsey Jones for her time on this project. The research conducted in the current study does not represent any conflict of interest for any of the above-listed authors.

\section{REFERENCES}

Aggleton JP, Neave N, Nagle S, Sahgal A. 1995. A comparison of the effects of medial prefrontal, cingulate cortex, and cingulum bindle lesions on test of spatial memory: Evidence of a double dissociation between frontal and cingulum bundle contributions. J Neurosci 15:7270-7281.

Alonso A, Garcia-Austt E. 1987. Neuronal sources of theta rhythm in the entorhinal cortex of the rat. I. Laminar distribution of theta field potentials. Exp Brain Res 67:493-501.

Amaral DG, Witter MP. 1989. The three-dimensional organization of the hippocampal formation: A review of anatomical data. Neurosci 31:571-591.

Barlow JS. 1964. Inertial navigation as a basis for animal navigation. J Theor Biol 6:76-117.

Biegler R, Morris R. 1996. Landmark stability: Studies exploring whether the perceived stability of the environment influences spatial representation. J Exp Biol 199:187-193.

Boccara CN, Sargolini F, Thoresen VH, Solstad T, Witter MP, Moser EI, Moser MB. 2010. Grid cells in pre- and parasubiculum. Nat Neurosci 13:987-994.

Boeijinga PH, Lopes da Silva FH. 1988. Differential distribution of $\beta$ and $\theta$ EEG activity in the entorhinal cortex of the rat. Brain Res 448:272-286.

Bohbot VD, Kalina M, Stepankova K, Spackova N, Petrides M, Nadel L. 1998. Spatial memory deficits in patients with lesions to the right hippocampus and to the right parahippocampal cortex. Neuropsychologia 36:1217-1238.

Brandon MP, Bogaard AR, Libby CP, Connerney MA, Gupta K, Hasselmo ME. 2011. Reduction of theta rhythm dissociates grid cell spatial periodicity from direction tuning. Science 332:595599.

Brown RW, Whishaw IQ. 2000. Similarities in the development of place and cue navigation by rats in a swimming pool. Devel Psychobiol 37:328-245.

Caballero-Bleda M, Witter MP. 1993. Regional and laminar organization of projections from the presubiculum and parasubiculum to the entorhinal cortex: An anterograde tracing study in the rat. J Comp Neurol 328:115-129.

Caballero-Bleda M, Witter MP. 1994. Projections from the presubiculum and the parasubiculum to morphologically characterized 
entorhinal-hippocampal projection neurons in the rat. Exp Brain Res 101:93-108.

Cacucci F, Lever C, Wills TJ, Burgess N, O'Keefe J. 2004. Thetamodulated place-by-direction cells in the hippocampal formation in the rat. J Neurosci 24:8265-8277.

Chen LL, Lin LH, Barnes CA, McNaughton BL. 1994a. Head-direction cells in the rat posterior cortex. II. Contributions of visual and ideothetic information to the directional firing. Exp Brain Res 191:24-34.

Chen LL, Lin LH Green EJ, Barnes CA, McNaughton BL. 1994b. Head-direction cells in the rat posterior cortex. I. Anatomical distribution and behavioral modulation. Exp Brain Res 191:8-23.

Cho J, Sharp PE. 2001. Head direction, place, and movement correlates for cells in the rat retrosplenial cortex. Behav Neurosci 115:325.

Clark BJ, Taube JS. 2011. Intact landmark control and angular path integration by head direction cells in the anterodorsal thalamus after lesions of the medial entorhinal cortex. Hippocampus 21:767-782.

Darwin C. 1873. Origin of certain instincts. Nature 7:417-418.

Drai D, Benjamini Y, Golani I. 2000. Statistical discrimination of natural modes of motion in rat exploratory behavior. J Neurosci Methods 96:119-131.

Eilam D, Golani I. 1989. Home base behavior of rats (Rattus norvegicus) exploring a novel environment. Behav Brain Res 34:199-211.

Etienne AS, Maurer R, Saucy F, Teroni E. 1986. Short-distance homing in the golden hamster after a passive outward journey. Anim Behav 34:696-715.

Frohardt RJ, Bassett JP, Taube JS. 2006. Path integration and lesions within the head direction cell circuit: Comparison between the roles of the anterodorsal thalamus and dorsal tegmental nucleus. Behav Neurosci 120:135-149.

Fyhn M, Molden S, Witter MP, Moser EI, Moser M-B. 2004. Spatial representation in the entorhinal cortex. Science 305:1258-1264.

Gaffan EA, Bannerman DM, Healey AN. 2000. Rats with hippocampal lesions learn about allocentric place cues in a non-navigational task. Behav Neurosci 114:895-906.

Galani R, Jarrard LE, Will BE, Kelche C. 1997. Effects of postoperative housing condition on functional recovery in rats with lesions of the hippocampus, subiculum, or entorhinal cortex. Neurobiol Learn Mem 67:43-56.

Galani R, Obis S, Coutureau E, Jarrard L, Cassel J-C. 2002. A comparison of the effects of fimbria-fornix, hippocampal, or entorhinal cortex lesions on spatial reference and working memory in rats: Short versus long postsurgical recovery period. Neurobiol Learn Mem 77:1-16.

Gallistel CR. 1990. The Organization of Learning. Cambridge, MA: MIT Press.

Glasgow SD, Chapman CA. 2007. Local generation of theta-frequency EEG activity in the parasubiculum. J Neurophysiol 97:3868-3879.

Gordon J, Ghilardi MF, Cooper SE, Ghez C. 1994. Accuracy of planar reaching movements. II. Systematic extent errors resulting from inertial anisotropy. Exp Brain Res 99:112-130.

Hafting T, Fyhn M, Molden S, Moser M-B, Moser EI. 2005. Microstructure of a spatial map in the entorhinal cortex. Nature 436:801-806.

Harker KT, Whishaw IQ. 2002. Impaired spatial performance in rats with retrosplenial lesions: Importance of the spatial problem and the rat strain in identifying lesion effects in a swimming pool. J Neurosci 22:1155-1164.

Harker KT, Whishaw IQ. 2004. Impaired place navigation in place and matching-to-place swimming pool tasks follows both retrosplenial cortex lesions and cingulum bundle lesions in rats. Hippocampus 14:224-231.

Hasselmo ME, Brandon MP. 2008. Linking cellular mechanisms to behavior: Entorhinal persistent spiking and membrane potential oscillations may underlie path integration, grid cell firing, and episodic memory. Neural Plast 658323:1-12.
Jeneson A, Squire LR. 2011. Working memory, long-term memory, and medial temporal lobe function. Learn Mem 19:15-25.

Jones CM, Braithwaite VA, Healy SD. 2003. The evolution of sex differences in spatial ability. Behav Neurosci 117:403-411.

Kerr KM, Agster KL, Furtak SC, Burwell RD. 2007. Functional neuroanatomy of the parahippocampal region: The lateral and medial entorhinal area. Hippocampus 17:697-708.

Kesner RP, Giles R. 1998. Neural circuit analysis of spatial working memory: Role of pre- and parasubiculum, medial and lateral entorhinal cortex. Hippocampus 8:416-423.

Knierim JJ, Hamilton DA. 2011. Framing spatial cognition: Neural representations of proximal and distal frames of references and their roles in navigation. Physiol Rev 91:1245-1279.

Köppen JR, Winter SS, Loda EL, Apger BP, Grimelli D, Hamilton DA, Wallace DG. In Press. Analysis of movement kinematics on analogous spatial learning tasks demonstrates conservation of direction and distance estimation across humans (Homo sapiens) and rats (Rattus norvegicus). J Comp Psychol.

Kubie JL, Fenton AA. 2009. Heading-vector navigation based on head-direction cells and path integration. Hippocampus 19:456479.

Maaswinkel H, Jarrard LE, Whishaw IQ. 1999. Hippocampectomized rats are impaired in homing by path integration. Hippocampus 9:553-561.

Markus EJ, Barnes CA, McNaughton BL, Gladden VL, Skaggs WE. 1994. Spatial information content and reliability of hippocampal CA1 neurons: Effects of visual input. Hippocampus 4:410-421.

Martin MM, Wallace DG. 2007. Selective hippocampal cholinergic deafferentation impairs self-movement cue use during a food hoarding task. Behav Brain Res 183:78-86.

Martin MM, Horn KL, Kusman KJ, Wallace DG. 2007. Medial septum lesions disrupt exploratory trip organization: Evidence for septohippocampal involvement in dead reckoning. Physio Behav 90:412-424.

Martin MM, Winter SS, Cheatwood JL, Carter LA, Jones JL, Weathered SL, Wagner SJ, Wallace DG. 2008. Organization of food protection behavior is differentially influenced by 192 IgG-saporin lesions of either the medial septum or the nucleus basalis magnocellularis. Brain Res 1241:122-135.

McKinney M, Coyle JT, Hedreen JC. 1983. Topographic analysis of the innervation of the rat neocortex and hippocampus by the basal forebrain cholinergic system. J Comp Neurol 217:103-121.

McNaughton BL, Leonard B, Chen L. 1989. Cortical-hippocampal interactions and cognitive mapping: A hypothesis based on reintegration of the parietal and inferotemporal pathways for visual processing. Psychobiology 17:230-235.

McNaughton BL, Barnes CA, Gerrard JL, Gothard K, Jung MW, Knierim JJ, Kudrimoti H, Qin Y, Skaggs WE, Suster M, Weaver KL. 1996. Deciphering the hippocampal polyglot: The hippocampus as a path integration system. J Exp Biol 199: 173-185.

McNaughton BL, Battaglia FP, Jensen O, Moser EI, Moser MB. 2006. Path integration and the neural basis of the 'cognitive map'. Nat Rev Neurosci 7:663-678.

Mesulam M-M, Mufson EF, Wainer BH, Levey AI. 1983. Central cholinergic pathways in the rat: An overview based on an alternative nomenclature. Neurosci 10:1185-1201.

Mitchell SJ, Ranck JB. 1980. Generation of theta rhythm in medial entorhinal cortex of freely moving rats. Brain Res 178:49-66.

Mitchell SJ, Rawlins JNP, Steward O, Olton DS. 1982. Medial septal area lesions disrupt $\theta$ rhythm and cholinergic staining in medial entorhinal cortex and produce impaired radial arm maze behavior in rats. J Neurosci 2:292-302.

Mittelstaedt ML, Mittelstaedt H. 1980. Homing by path integration in a mammal. Naturwissenschaften 67:566-567.

Morasso P. 1981. Spatial control of arm movements. Exp Brain Res 42:223-227. 
Morris RGM, Garrud P, Rawlins JNP, O'Keefe J. 1982. Place navigation impaired in rats with hippocampal lesions. Nature 297:681-683.

Moser EI, Moser M-B. 2008. A metric for space. Hippocampus 18:1142-1156.

Muller RU, Kubie JL. 1987. The effects of changes in the environment on the spatial firing of hippocampal complex-spike cells. J Neurosci 77:1951-1968.

Neave N, Lloyd S, Sahgal A, Aggleton JP. 1994. Lack of effect of lesions in the anterior cingulate cortex and retrosplenial cortex on certain test of spatial memory in the rat. Behav Brain Res 65:89101.

Neitz J, Jacobs GH. 1986. Reexamination of spectral mechanisms in the rat (Rattus norvegicus). J Comp Psychol 100:21-29.

Oddie SD, Kirk IJ, Whishaw IQ, Bland BH. 1997. Hippocampal formation is involved in movement selection: Evidence from medial septal cholinergic modulation and concurrent slow-wave (theta rhythm) recording. Behav Brain Res 88:169-180.

O'Keefe J, Burgess N. 2005. Dual phase and rate coding in hippocampal place cells: Theoretical significance and relationship to entorhinal grid cells. Hippocampus 15:853-866.

O'Keefe J, Dostrovsky J. 1971. The hippocampus as a spatial map. Preliminary evidence from unit activity in the freely-moving rat. Brain Res 34:171-175.

O'Keefe J, Nadel L. 1978. The Hippocampus as a Cognitive Map. Oxford: Clarendon Press.

O'Keefe J, Speakman A. 1987. Single unit activity in the rat hippocampus during a spatial memory task. Exp Brain Res 68:1-27.

Parron C, Save E. 2004. Evidence for entorhinal and parietal cortices involvement in path integration in the rat. Exp Brain Res 159:349-359.

Parron C, Poucet B, Save E. 2004. Entorhinal cortex lesions impair the use of distal but not proximal landmarks during place navigation in the rat. Behav Brain Res 154:345-352.

Philbeck JW, Behrmann M, Levy L, Potolicchio SJ, Caputy AJ. 2004. Path integration deficits during linear locomotion after human medial temporal lobectomy. J Cogn Neurosci 16:510-520.

Quirk GJ, Muller RU, Kubie JL. 1990. The firing of hippocampal place cells in the dark depends on the rat's recent experience. J Neurosci 10:2008-2017.

Sargolini F, Fyhn M, Hafting T, McNaughton BL, Witter MP, Moser M-B, Moser EI. 2006. Conjunctive representation of position, direction, and velocity in entorhinal cortex. Science 312:758-762.

Semenov LV, Bures J. 1989. Vestibular stimulation disrupts acquisition of place navigation in the Morris water tank task. Behav Neural Biol 51:346-363.

Steffenach H-A, Witter M, Moser M-B, Moser EI. 2005. Spatial memory in the rat requires the dorsolateral band of the entorhinal cortex. Neuron 45:301-313.

Sutherland RJ, Kolb B, Whishaw IQ. 1982. Spatial mapping: Definitive disruption by hippocampal or medial frontal cortical damage in the rat. Neurosci Lett 31:271-276.

Talk AC, Kang E, Gabriel M. 2004. Independent generation of theta rhythm in the hippocampus and posterior cingulate cortex. Brain Res 1015:15-24.

Taube JS. 2007. The head direction signal: Origins and sensory-motor integration. Annu Rev Neurosci 21:181-207.
Taube JS, Muller RU, Ranck JB. 1990a. Head-direction cells recorded from the postsubiculum in freely moving rats. I. Description and quantitative analysis. J Neurosci 10:420-435.

Taube JS, Muller RU, Ranck JB. 1990b. Head-direction cells recorded from the postsubiculum in freely moving rats. II. Effects of environmental manipulations. J Neurosci 10:436-447.

Tchernichovski O, Golani I. 1995. A phase plane representation of rat exploratory behavior. J Neurosci Methods 62:21-27.

Tchernichovski O, Benjamini Y, Golani I. 1998. The dynamics of long-term exploration in the rat. Biol Cybern 78:423-432.

Tolman EC, Ritchie BF, Kalish D. 1946. Studies in spatial learning. I. Orientation and the short-cut. J Exp Psychol 36:13-24.

van Groen T, Wyss JM. 1990. The postsubicular cortex in the rat: Characterization of the fourth region of the subicular cortex and its connections. Brain Res 529:165-177.

Vertes RP, Hoover WB, Di Prisco GV. 2004. Theta rhythm of the hippocampus: Subcortical control and functional significance. Behav Cog Neurosci Rev 3:173-200.

Wallace DG, Whishaw IQ. 2003. NMDA lesions of Ammon's horn and the dentate gyrus disrupt the direct and temporally paced homing displayed by rats exploring a novel environment: Evidence for a role of the hippocampus in dead reckoning. Euro J Neurosci 18:513-523.

Wallace DG, Hamilton DA, Whishaw IQ. 2006. Movement characteristics support a role for dead reckoning in organizing exploratory behavior. Anim Cogn 9:219-228.

Wallace DG, Martin MM, Winter SS. 2008. Fractionating dead reckoning: Role of the compass, odometer, logbook, and home base establishment in spatial orientation. Naturwissenschaften 95:1011-1026.

Whishaw IQ. 1998. Place learning in hippocampal rats and the path integration hypothesis. Neurosci Biobehav Rev 22:209-220.

Whishaw IQ, Vanderwolf CH. 1973. Hippocampal EEG and behavior: Changes in amplitude and frequency of RSA (theta rhythm) associated with spontaneous and learned movement patterns in rats and cats. Behav Biol 8:461-484.

Whishaw IQ, Hines DJ, Wallace DG. 2001a. Dead reckoning (path integration) requires the hippocampal formation: Evidence from spontaneous exploration and spatial learning tasks in light (allothetic) and dark (idiothetic) tests. Behav Brain Res 127:49-69.

Whishaw IQ, Maaswinkel H, Gonzalez CL, Kolb B. 2001b. Deficits in allothetic and idiothetic spatial behavior in rats with posterior cingulate cortex lesions. Behav Brain Res 118:67-76.

Winson J. 1978. Loss of hippocampal theta rhythm results in spatial memory deficit in the rat. Sci 201:160-163.

Winter SS, Wagner SJ, McMillin JL, Wallace DG. 2011. Mammillothalamic tract lesions disrupt dead reckoning in the rat. Euro J Neurosci 33:371-381.

Wolber T, Wiener JM, Mallot HA, Buchel C. 2007. Differential recruitment of the hippocampus, medial prefrontal cortex, and the human motion complex during path integration in humans. J Neurosci 27:9408-9416.

Woolf NJ, Eckenstein F, Butcher LL. 1984. Cholinergic systems in the rat brain. I. Projections to the limbic telencephalon. Brain Res Bull 13:751-784. 